\title{
The role of somatostatin analogues in treatment of TSH secreting pituitary adenomas
}

\author{
Wojciech Zgliczyński ${ }^{1 *}$, Piotr Zdunowski ${ }^{1}$, Izabella Czajka-Oraniec ${ }^{1}$, Wojciech Jeske', Grzegorz Zieliński ${ }^{2}$ \\ From 4th Congress of the Polish Thyroid Association 2013 \\ Lodz, Poland. 11-13 April 2013
}

\section{Background}

TSH-secreting tumours are extremely rare case of hyperthyroidism. Most important clinical feature is preserved TSH level in subjects with apparent thyrotoxicosis. Possible misdiagnosis of primary thyroid hyperfunction could lead to mistreatment with anti-thyroid medications. This worsens disease course and outcome. Neurosurgery success rate is limited by tumour size and its extrasellar expansion. Native somatostatin is key negative regulator of TSH secretion. In most cases tumour cells express somatostatin receptors. This feature creates potential use of somatostatin analogues for medical treatment of TSHsecreting tumours.

\section{Aim of the study}

The aim was to determine potential value of somatostatin analogues in primary TSH-oma treatment. Secondary objective was to evaluate efficacy of long-acting somatostatin analogues in cases after unsuccessful neurosurgery.

\section{Material}

Material comprised of 17 patients with secondary thyrotoxicosis, 7 women and 10 men, aged 20 to 69 years (mean 39), presenting with pituitary macroadenoma (16) and one with microadenoma and empty sella. Before diagnosis was established 8 out of 17 patients received antithyroid medication, in 2 cases strumectomy was performed and 2 patients received 131I therapy.

\section{Intervention}

Somatostatin analogue octreotide long acting repeatable (LAR) administration at least 3 months (3 injections) before surgery, and in cases of unsuccessful surgery stable octreotide LAR therapy.

'Department of Endocrinology, Medical Centre of Postgraduate Education, Warsaw, Poland

Full list of author information is available at the end of the article

\section{Results}

Initially, all patients had elevated fT4 and $\alpha$-SU levels

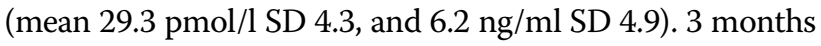
of octreotide LAR therapy led to significant fT4 reduction (to mean $12.2 \mathrm{pmol} / \mathrm{l}$ ) and TSH reduction from mean $6.5 \mathrm{mIU} / \mathrm{ml}$ to $0.3 \mathrm{mIU} / \mathrm{l})$. In all cases clinical improvement was observed.

In 14 out of 17 pre-treated with octreotide LAR decreased tumour volume and in 2 improvement in visual field was observed.

Patients in euthyroid state were referred to neurosurgery department. Transsphenoidal adenomectomy was successful 13 out of 17. In four cases after unsuccessful neurosurgery intervention stable euthyroidism was achieved with octreotide LAR treatment. In one case secondary thyrotoxicosis relapsed 2 years and now is controlled by octreotide treatment.

\section{Conclusions}

Somatostatin analogue treatment is efficient in TSHsecreting tumours in the terms of TSH secretion, thyroid function and clinical improvement. In cases of surgery failure prolonged octreotide treatment could be safe and efficient option of disease management.

\section{Author details}

'Department of Endocrinology, Medical Centre of Postgraduate Education, Warsaw, Poland. ${ }^{2}$ Department of Neurosurgery, Military Institute of Medicine, Warsaw, Poland.

Published: 5 April 2013

doi:10.1186/1756-6614-6-S2-A64

Cite this article as: Zgliczyński et al:: The role of somatostatin analogues in treatment of TSH secreting pituitary adenomas. Thyroid Research 2013 6(Suppl 2):A64.

\section{() Biomed Central}

(C) 2013 Zgliczyński et al; licensee BioMed Central Ltd. This is an Open Access article distributed under the terms of the Creative Commons Attribution License (http://creativecommons.org/licenses/by/2.0), which permits unrestricted use, distribution, and reproduction in any medium, provided the original work is properly cited. 